\title{
VINCULAÇÃO GENÉTICA COMO FERRAMENTA PARA TITULAÇÃO DAS TERRAS REMANESCENTES QUILOMBOLAS
}

Carla Costa Gomes, Josemar Vinicius Maiworm Abreu Silva, Rodrigo Grazinoli Garrido, Carolina Conceição Bottino Gruszkowski, Ana Lucia Cardoso Alves

Universidade Católica de Petrópolis, Curso de Biomedicina, Petrópolis, RJ. e-mail: carla.costag@gmail.com

\section{RESUMO}

O objetivo deste estudo foi comprovar o histórico de endogamia, as relações de parentesco e ancestralidade dos moradores do Quilombo da Tapera (RJ), com o intuito de facilitar o processo de titulação das terras em que vivem. Com essa finalidade foi construída a árvore genealógica da população, além de estudos de short tanden repeats autossômicos (STRs) e Y-STRs (STRS presentes no cromossomo Y). Participaram do trabalho 47 voluntários moradores da comunidade que forneceram documentação legal para a construção da árvore genealógica e amostras de mucosa oral para os estudos genéticos. A genealogia demonstrou que todos os moradores nascidos no quilombo descendem dos indivíduos 1 e /ou 47, atestando o histórico de endogamia. Os vínculos genéticos descritos entre os participantes foram confirmados e a análise de ancestralidade sugere que durante a sua formação, a comunidade contou com indivíduos de origem africana, além de indivíduos com origem em homens europeus.

Palavras-chave: vínculo genético, genética de população, quilombo, titulação de terras.

\section{GENETIC BONDING AS A TOOL FOR “QUILOMBOLA” REMNANTS LAND TITLE}

\begin{abstract}
The objective of this study was to prove the endogamy history, family relationships and ancestry of Quilombo da Tapera (RJ) residents, in order to facilitate the process of land title where they live. For this purpose, the family tree of the population was built, in addiction short tanden repeats autosomes (STRs) and Y-STRs (STRS present on the Y chromosome) studies. Participated in the study 47 community residents volunteers who provided legal documentation for the construction of the family tree and samples of oral mucosa for genetic studies. The genealogy shows that all residents born in quilombo descend from 1 and/or 47 individuals, proving the endogamy history. Genetic bonds described among participants were confirmed and ancestry analysis suggests that during the formation, the community had individuals of African origin, as well as European men ones.
\end{abstract}

Keywords: genetic bond, population genetics, quilombo, land title. 


\section{INTRODUÇÃO}

O tráfico negreiro no Brasil se estendeu do século XVI ao XIX, ocasião em que o país recebeu cerca de 5,5 milhões de escravos africanos, cerca de $40 \%$ do total de escravos comercializados $^{1}$. Durante a história da escravidão surgiram pelo Brasil numerosos quilombos, comunidades formadas em sua maioria pelo processo de resistência à escravidão, onde os escravos fugidos ocupavam regiões de difícil acesso e restabeleciam o modo de vida em liberdade. Estes quilombos deram origem aos grupos remanescentes quilombolas, comunidades formadas pelos descendentes dos escravos negros que constituíam os quilombos.

Apenas após um século de abolição da escravatura, o debate sobre as comunidades quilombolas retornou ao campo jurídico-político durante as discussões do processo de formulação da Constituinte de 1988, consagrando no Artigo 68 o direito à propriedade de suas terras. De fato, - Artigo 68 marca a possibilidade de reparação histórica à referida população, entretanto, diversos movimentos sociais de remanescentes quilombolas ainda lutam pelo acesso, garantia e manutenção de suas terras, importante mecanismo de legitimação e reconhecimento da contribuição para formação sociocultural do Brasil $^{2}$.

Embora o Artigo 68 da Constituição determine a posse das terras aos "remanescentes das comunidades quilombolas", 0 reconhecimento da comunidade transcende a observação da descendência de escravos ou da formação durante o período escravocrata, mas a existência e manutenção do patrimônio imaterial cultural, que reverbera em tradições, costumes, valores, relação com a natureza, religiosidade, saberes e na vida social coletiva da comunidade ${ }^{2}$.

A titulação, a última etapa de um longo processo encabeçado pelo Instituto Nacional de Colonização e Reforma Agrária (INCRA) ${ }^{3}$, é um importante dispositivo jurídico que permite preservar o patrimônio histórico, social e cultural das comunidades quilombolas ${ }^{4}$. Fica assegurada, desta forma, a inalienabilidade, a imprescritibilidade e a impenhorabilidade das terras tituladas, protegendo a comunidade da especulação imobiliária, de conflitos com mineradoras e de grandes produtores rurais, assim como projetos de modernização e infraestrutura do próprio Estado, como a construção de rodovias e barragens de usina hidrelétrica ${ }^{2,4}$.
Apesar da existência de um arcabouço jurídico que confere proteção as terras ocupadas por remanescentes quilombolas, existem mais de mil processos para titulação de terras abertos no INCRA; cerca de 1.500 comunidades reconhecidas e registradas no Cadastro Geral de Remanescentes das Comunidades dos Quilombos da Fundação Cultural Palmares (FCP), etapa necessária para abertura de processo de titulação no INCRA; e de três a cinco mil comunidades com possibilidade de requerer o reconhecimento e, consequentemente, pleitear a titulação ${ }^{2}$. Neste cenário, menos de $20 \%$ dos processos abertos no INCRA resultam na titulação definitiva ${ }^{2} \mathrm{e}$, atualmente, apenas 253 comunidades são tituladas, repensando (representando) cerca de $8 \%$ do total de comunidades existentes no país ${ }^{5}$.

A demora no processo de titulação das terras deve-se, em parte, ao grande número de procedimentos burocráticos exigidos não só pelo governo federal, mas também por governos estaduais, que constam com legislações próprias acerca do assunto ${ }^{5}$.

O Quilombo da Tapera é uma comunidade remanescente quilombola situada no Vale da Boa Esperança, no município de Petrópolis, localizado na região serrana do Estado do Rio de Janeiro, composta atualmente por 13 famílias, totalizando 54 pessoas.

A região onde hoje se localiza o quilombo fazia parte da Fazenda Santo Antônio de propriedade de Agostinho Corrêa da Silva Goulão, que faleceu em 1847, deixando em testamento a liberdade para todos os seus escravos e um sítio, na região da Tapera, para uma escrava chamada Isabel. Grande parte dos escravos libertos de Goulão passou a morar no sítio recebido por Isabel a partir de 1849 , dando origem ao Quilombo da Tapera. A comunidade passou a ser reconhecida como remanescente quilombola no ano de 2011 quando recebeu o título da FCP e desde então luta para conseguir também e titulação de suas terras.

Os moradores do Quilombo da Tapera relatam um grande histórico de endogamia, que durante os anos teria sido responsável pela manutenção de indivíduos com os mesmos ascendentes na comunidade. Desta forma, o trabalho buscou comprovar o histórico de endogamia, relações de parentesco existentes entre a população e ancestralidade, já que estes dados podem ser úteis na demonstração de que os atuais moradores da comunidade são descendentes dos escravos que fundaram o 
quilombo, e assim, terem grande valia na composição do levantamento antropológico do Relatório Técnico de Identificação e Delimitação (RTID) elaborado pelo INCRA durante o processo de titulação das terras em que vivem.

\section{METODOLOGIA}

O estudo abrangeu 47 voluntários (24 homens e 23 mulheres), todos moradores da comunidade Quilombo da Tapera que forneceram documentação legal (Registro Geral, Certidões de Nascimento e Certidões de Casamento) acerca de seus núcleos familiares para confecção da árvore genealógica, além de fornecerem amostras de mucosa oral para os estudos de vínculos genéticos e análise de ancestralidade. $O$ trabalho foi aprovado pelo Comitê de Ética em Pesquisa (CEP) da Universidade Católica de Petrópolis sendo registrado sob o $\mathrm{n}$ 0 1.552.568.

A demonstração das relações endogâmicas foi feita através da produção da árvore genealógica da população, sendo os dados obtidos através de relatos da população e da análise de documentação legal fornecida pelos voluntários. A árvore foi confeccionada com o auxílio do programa MyHeritage Family Tree Builder Genealogy.

Após a confecção da árvore genealógica, vínculos genéticos (entre pais e filhos e entre irmãos) existentes entre os voluntários, foram confirmados através da análise de 24 marcadores moleculares STRs (short tanden repeats) presentes em autossomos. O DNA foi obtido através das amostras de mucosa oral fornecidas pelos voluntários e armazenadas em papel FTA. A amplificação das regiões de interesse foi feita com a utilização do kit comercial PowerPlex Fusion System (Promega) e para o preparo do mix de reação foram utilizados $7,5 \mu \mathrm{L}$ de água, $2,5 \mu \mathrm{L}$ de PowerPlex Fusion 5X Master Mix, 2,5 $\mu \mathrm{L}$ de PowerPlex Fusion $5 X$ Primer Pair Mix e 1 punch $(1,2 \mathrm{~mm})$ de papel FTA com amostra de DNA armazenada. $O$ protocolo de ciclos de amplificação utilizado foi o sugerido no manual do fabricante do Kit, sendo composto de 27 ciclos (cada um constituído por 1 minuto a $96^{\circ} \mathrm{C}, 10$ segundos a $94^{\circ} \mathrm{C}, 1$ minuto a $59^{\circ} \mathrm{C}$ e 30 segundos a $72^{\circ} \mathrm{C}$ ) seguido de uma extensão final de 20 minutos a $60^{\circ} \mathrm{C}$. Os produtos amplificados foram submetidos à eletroforese capilar e os perfis obtidos analisados através do programa GeneMapper ID-X.
Os dados referentes a cada um dos alelos encontrados para os loci estudados foram inseridos em uma planilha do programa Microsoft Excel ${ }^{\text {Tm}}$ e comparados para obtenção da probabilidade de vínculo genético, levando-se em consideração os alelos que os possíveis indivíduos aparentados compartilham e a frequência dos mesmos na população do estado do Rio de Janeiro $^{6}$. A análise foi feita entre os dois pais, ou um dos pais (dependendo da adesão ao projeto) e seus filhos ou no caso de não participação dos pais, a análise foi feita entre irmãos.

A pesquisa da ancestralidade foi feita por meio do estudo de Y-STRs, marcadores de DNA específicos de indivíduos do sexo masculino que permitem o estudo das linhagens paternas. Nesta etapa foram excluídas as amostras de voluntários que não tenham nascido ou que sejam filhos de homens que não tenham nascido na comunidade estudada, tendo-se um total de 22 amostras aptas para a análise.

A amplificação de 23 Y-STRs foi feita com a utilização do Kit comercial PowerPlex ${ }^{\circ}$ Y23 System (Promega) e para o preparo do mix de reação foram utilizados $8,75 \mu \mathrm{L}$ de água, $2,5 \mu \mathrm{L}$ de PowerPlex Y23 5X Master Mix, 1,25 $\mu \mathrm{l}$ de PowerPlex ${ }^{\circ}$ Y23 10X Primer Pair Mix e 1 punch $(1,2 \mathrm{~mm})$ de papel FTA com amostra de DNA armazenada. $O$ protocolo de ciclos de amplificação utilizado foi o sugerido pelo fabricante do kit, sendo composto por 26 ciclos (cada um constituído por 2 minutos a $96^{\circ} \mathrm{C}, 10$ segundos a $94^{\circ} \mathrm{C}, 1$ minuto a $61^{\circ} \mathrm{C}$ e 30 segundos a $72^{\circ} \mathrm{C}$ ), sendo seguido por uma extensão final de 20 minutos a $60^{\circ} \mathrm{C}$. Os produtos amplificados foram submetidos a eletroforese capilar e os perfis obtidos analisados pelo programa GeneMapper ID-X.

Os dados referentes aos perfis de Y-STRs foram inseridos na página da web Haplogroups Predictor (https://hprg.com/hapest5) onde foram obtidos os respectivos haplogrupos $e$ as informações sobre a região de origem de cada um deles.

\section{RESULTADOS}

De acordo com os dados obtidos foi possível construir a árvore genealógica da população composta por seis gerações (Figura 1). Até onde foi possível averiguar todos os nascidos na comunidade são descendentes do indivíduo 1 e/ou do indivíduo 47. Para melhor visualização da composição da população os descendentes de 1 estão coloridos de vermelho e os descendentes 
de 47 estão marcados de azul. Aqueles que são descendentes de ambos apresentam as duas cores. Os indivíduos que não apresentam coloração vermelha nem azul são aqueles não nascidos no quilombo, indivíduos de fora que fixaram residência na comunidade. Como as relações de parentesco entre os moradores são muito próximas, alguns indivíduos aparecem de forma repetida na árvore por serem representados em mais de um núcleo. Para facilitar a compreensão a Figura 2 mostra o percentual de descendentes de 1 , de 47 , de ambos e de fora da comunidade entre os indivíduos vivos.

O estudo dos STRs confirmou as relações de parentesco descritas entre os indivíduos analisados, os resultados obtidos estão demonstrados na Tabela 1.

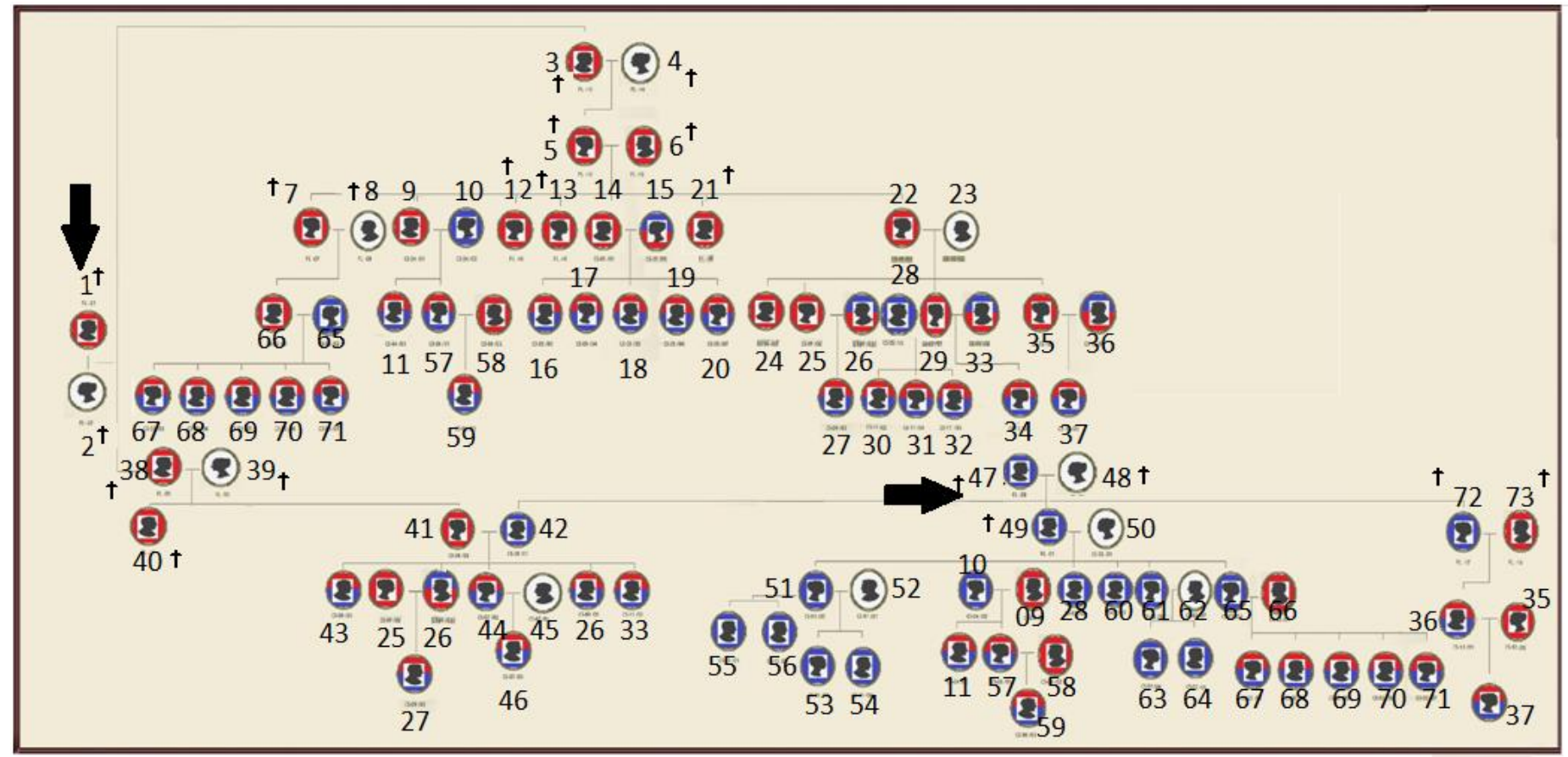

Figura 1. Árvore genealógica da população. Vermelho: Descendentes de 1. Azul: Descendentes de 47. Duas cores: Descendentes de 1 e 47. Sem coloração: Nascidos fora da comunidade. Símbolo t: Falecidos.

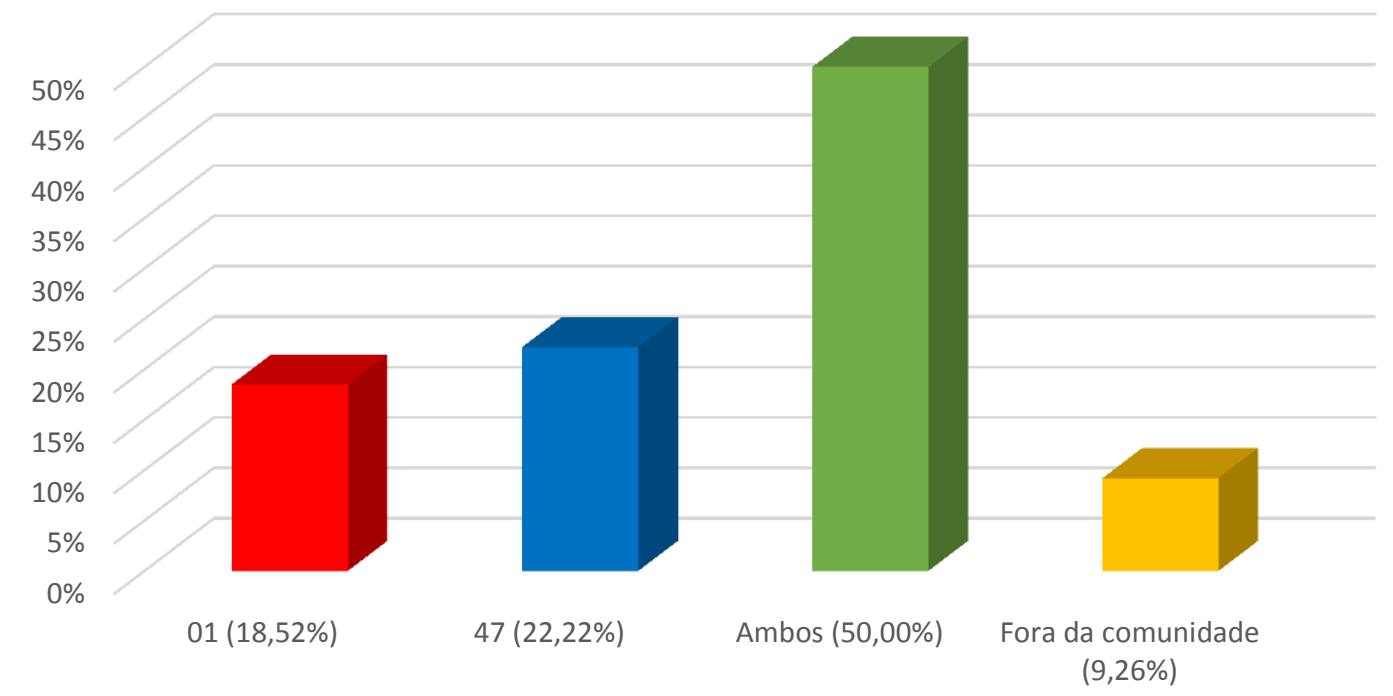

Figura 2. Percentagem de descendentes entre indivíduos vivos segundo documentação legal 
Tabela 1. Resultados das análises de probabilidades de vínculos genéticos.

\begin{tabular}{cccc}
\hline Mãe & Pai & Filho(a) & Probalidade \\
\hline 51 & --- & 53 & 99,9999999996948800 \\
\hline 51 & --- & 54 & 99,999999944728500 \\
\hline 51 & --- & 55 & 99,9999999947516600 \\
\hline 50 & --- & 51 & 99,999996801308600 \\
\hline 50 & --- & 60 & 99,999988499657600 \\
\hline 50 & --- & 65 & 99,999983084282700 \\
\hline 65 & 66 & 71 & 99,999999999999999 \\
\hline 65 & 66 & 67 & 99,9999999999999999 \\
\hline 65 & 66 & 68 & 99,999999999999999 \\
\hline 65 & 66 & 69 & 99,999999999999999 \\
\hline 65 & 66 & 70 & 99,9999999999999999 \\
\hline--- & 14 & 17 & 99,999999996749100 \\
\hline--- & 14 & 18 & 99,999703550008500 \\
\hline--- & 14 & 19 & 99,9999999994484400 \\
\hline--- & 14 & 20 & 99,999999999684500 \\
\hline 44 & 45 & 46 & 99,9999999999999999 \\
\hline 41 & 42 & 43 & 99,999999999999999 \\
\hline 41 & 42 & 44 & 99,999999999999999 \\
\hline 41 & 42 & 26 & 99,9999999999999999 \\
\hline 41 & 42 & 33 & 99,999999999999999 \\
\hline 25 & 26 & 27 & 99,9999999999999999 \\
\hline 22 & --- & 25 & 99,999999999953700 \\
\hline 22 & --- & 29 & 99,999999999987000 \\
\hline 22 & --- & 35 & 99,9999999999812300 \\
\hline 29 & --- & 30 & 99,999999741862600 \\
\hline 29 & --- & 31 & 99,9999999996695500 \\
\hline 29 & --- & 32 & 99,999999852114500 \\
\hline 29 & 33 & 34 & 99,999999999999999 \\
\hline 35 & 36 & 37 & 99,9999999999999999 \\
\hline Irmão 1 & Irmão 2 & Probabilidade \\
\hline & 14 & 22 & 99,9999999854693700 \\
\hline & 63 & 64 & 99,9999999984970900 \\
\hline & & & \\
\hline 5 & &
\end{tabular}

A análise dos Y-STRs revelou a presença de 2 haplogrupos distintos na população estudada (Tabela 2). Dentre os 23 indivíduos analisados, 11 apresentaram o haplogrupo E1bla e 11 o haplogrupo R1b.

Tabela 2. Haplogrupos encontrados na população

\begin{tabular}{ccc}
\hline Haplogrupo & Origem & $\begin{array}{c}\text { \% População } \\
\text { analisada }\end{array}$ \\
\hline E1bla & África & $50,00 \%$ \\
\hline R1b & Europa ocidental & $50,00 \%$ \\
\hline
\end{tabular}

\section{DISCUSSÃO}

A árvore genealógica demonstra que todos os nascidos no quilombo entre as gerações analisadas descendem os indivíduos 1 e/ou 47. A distribuição de cores de acordo com o padrão de descendência evidencia as relações endogâmicas mantidas na comunidade, relações tais que permitiram que ao longo dos anos a comunidade mantivesse um caráter familiar, onde as 13 famílias constituintes do quilombo são representadas dentro da mesma genealogia.

A genealogia pode nortear a busca por novos registros que sejam capazes de identificar os constituintes das gerações anteriores havendo a possibilidade de identificação dos escravos que fundaram a comunidade, já que esta é relativamente nova contando com apenas 167 anos de existência, além de eventualmente comprovar que os moradores do quilombo são descendentes de tais fundadores. De acordo com os relatos dos moradores os indivíduos 1 e 47 também seriam aparentados, possivelmente primos em 1으, grau, fato que não se pôde fundamentar pela falta de documentação disponível, porém caso a informação fosse comprovada, todos os atuais moradores nascidos na comunidade teriam um mesmo ancestral comum.

Em relação a grande contribuição europeia na linhagem patrilinear dos moradores encontrada através do estudo de Y-STRs não é uma surpresa quando levamos em consideração os relatos históricos de que durante o período da escravidão era comum que os senhores de fazenda assim como seus funcionários mantivessem relações íntimas com as escravas. O haplogrupo R1b, característico da Europa Ocidental, está presente em mais de $50 \%$ dos homens portugueses o que evidencia ainda mais a possibilidade de que os resultados obtidos reflitam as relações dos colonizadores com escravas africanas. Os resultados obtidos corroboram com os encontrados em outros estudos $^{7,8,9}$ onde se verificou maior contribuição europeia na constituição genética de descendentes quilombolas quando STRs presentes no cromossomo $Y$ foram objeto de estudo. Como nos outros estudos citados, é provável que a análise da linhagem matrilínea da população revelasse uma predominância africana, contudo na população em estudo tal análise não é possível pela falta de descendentes vivos que carregam o DNA Mitocondrial (DNAmt) original. A existência dos laços de 
consanguinidade entre os moradores nos permite inferir que o resultado obtido se estende de forma geral também às moradoras da comunidade.

O estudo demonstrou que a prática da endogamia vivenciada pela população do Quilombo da Tapera foi responsável pela manutenção da comunidade como um grande grupo familiar ao longo dos anos. Já os resultados obtidos pela análise de ancestralidade sugerem que durante a sua formação a comunidade contou com indivíduos de origem africana, além de indivíduos com origem em homens europeus, possivelmente portugueses.

\section{CONFLITO DE INTERESSE}

Os autores declaram não haver qualquer potencial de conflito de interesse que possa interferir na imparcialidade deste trabalho científico.

\section{REFERÊNCIAS}

1. Emory University. Voyages, The Trans-Atlantic Slave Trade Database [Internet]. 2013 [Acesso em 30 Jul 2016]. Disponível em: http://slavevoyages.org/assessment/estimates

2. Monteiro GRF. O quilombo em questão: sobreposições e insurgências a partir do conflito socioambiental e territorial da comunidade negra do Grotão no Parque Estadual da Serra da Tiririca. Ensaios Geogr. 2015;4(8):28-48.

3. Comissão Pró-índio de São Paulo. O caminho da titulação [Internet]. [Acessado em 31 Jul 2016]. Disponível em: http://www.cpisp.org.br/terras/html/comosetitul a caminho.aspx

4. Maia PM de C. Ladeira Sacopã, 250: um parque, um quilombo, um conflito sócioambiental na Lagoa Rodrigo de Freitas. Rev VITAS - Visões Transdiscipl sobre Ambient e Soc. 2011;i(1):251-74.

5. Comissão Pró-índio de São Paulo. Por que as titulações não acontecem? [Internet]. Terras Quilombolas. [Acesso em 31 Jul 2016]. Disponível em:

http://www.cpisp.org.br/terras/html/por que as titulacoes nao acontecem.aspx

6. Hessab T, Carvalho RM, Souza M, Martha SFP, Garrido RG, Freitas NF et al. Genetic data on 17 STR autosomal loci for a sample population of the State of Rio de Janeiro, Brazil. Forensic Sci Int Genet. 2015;14:e4-5.

DOI: http://dx.doi.org/10.1016/j.fsigen.2014.10.001

7. Pedrosa MAF. Composição genética de quatros populações remanescentes de quilombos do Brasil com base em microssatélites e marcadores de ancestralidade [Dissertação]. Brasília: Universidade de Brasília; 2006.

8. Barcelos RSS. Diversidade Genética das Populações do Centro-Oeste: DNA Mitocondrial e Cromossomo Y [Tese]. Brasília: Universidade de Brasília; 2006.

9. Souza LIM. Variabilidade Molecular do Cromossomo Y em Remanescentes de Quilombos do Vale do Ribeira [Dissertação]. São Paulo: Universidade de São Paulo; 2003. https://doi.org/10.11606/d.41.2003.tde19032004-091243

Recebido para publicação em 19/08/2016

Revisado em 25/08/2016

Aceito em 06/09/2016 